
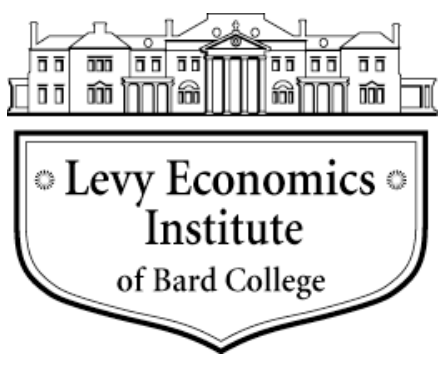

Working Paper No. 755

\title{
The Economics of Inclusion: Building an Argument for a Shared Society
}

by

\author{
Michael A. Valenti and Olivier G. Giovannoni \\ Economists for Peace and Security*
}

\section{February 2013}

\footnotetext{
* Economists for Peace and Security, c/o Levy Institute of Bard College, Box 5000, Annandale-on-Hudson, NY 12504. www.epsusa.org. The authors owe extensive thanks to Thea Harvey and Clem McCartney for their support and commentary.
}

The Levy Economics Institute Working Paper Collection presents research in progress by Levy Institute scholars and conference participants. The purpose of the series is to disseminate ideas to and elicit comments from academics and professionals.

Levy Economics Institute of Bard College, founded in 1986, is a nonprofit, nonpartisan, independently funded research organization devoted to public service. Through scholarship and economic research it generates viable, effective public policy responses to important economic problems that profoundly affect the quality of life in the United States and abroad.

$$
\begin{gathered}
\text { Levy Economics Institute } \\
\text { P.O. Box 5000 } \\
\text { Annandale-on-Hudson, NY 12504-5000 } \\
\text { http://www.levyinstitute.org }
\end{gathered}
$$

Copyright (C Levy Economics Institute 2013 All rights reserved 


\begin{abstract}
This paper presents a review of the literature on the economics of shared societies. As defined by the Club de Madrid, shared societies are societies in which people hold an equal capacity to participate in and benefit from economic, political, and social opportunities regardless of race, ethnicity, religion, language, gender, or other attributes, and where, as a consequence, relationships between the groups are peaceful. Our review centers on four themes around which economic research addresses concepts outlined by the Club de Madrid: the effects of trust and social cohesion on growth and output, the effect of institutions on development, the costs of fractionalization, and research on the policies of social inclusion around the world.
\end{abstract}

Keywords: Shared Societies; Economic Inclusion; Institutions; Economic Growth; Income Distribution

JEL Classifications: D31, O11, O43 


\section{INTRODUCTION: WHAT IS A SHARED SOCIETY?}

This paper takes on the difficult task of providing a review of economic literature pertinent to establishing an economic rationale for the Club de Madrid's vision of shared societies. The Club de Madrid (2010, p. 1) defines a "shared society" as one in which "people hold an equal capacity to participate in, and benefit from, economic, political and social opportunities regardless of race, ethnicity, religion, language, and other attributes, and where, as a consequence, relations between the groups are peaceful."

Let us start by defining the contours of a shared society. While on the one hand, the Club de Madrid believes that "specific characteristics of shared societies will vary across countries and regions," shared societies are, in effect, those in which all people are equally capable of participation in and reaping the benefits of economic, political, and social opportunities (Ibid., emphasis added). Residents in a shared society have a sense of belonging, and are empowered to participate without necessarily conforming to a dominant culture. A shared society has a stable policy environment and legal system. Implementation of a shared society means seeking to develop workable means by which to include marginal groups. A shared society seeks to facilitate trade between different communities, thereby accessing the potential earning power and innovation of social groups who, in a fractionalized society, are marginalized. A shared society is one in which, ideally, economic growth and development are bolstered by newly included groups and more equitable and sustainable economic growth for all of its citizens.

It is often far easier to find literature that demonstrates the cost of fractionalization than it is to find literature that demonstrates nations that are reaping the rewards of social inclusion. We outline the methodology in constructing the economic argument below.

While it is the position of this paper that a shared society is inherently desirable, the construction of an economic rationale presents a bit of a challenge for essentially two reasons. First, it is important to acknowledge that the term "shared societies" is a new concept. As a result, the economic literature is limited and scattered, since it does not fall into a precise area of economic research, such as money and banking, international trade, or any other Journal of Economic Literature (JEL) classification. ${ }^{1}$ Second, the concept of a shared society does not

\footnotetext{
${ }^{1} \mathrm{JEL}$ is a flagship journal of the American Economic Association, and provides the standard classification themes for all economic research. See: http://www.aeaweb.org/jel/jel_class_system.php.
} 
necessarily always cover a quantifiable ground, for the idea of a shared society often has qualitative - as opposed to quantitative - meanings.

Despite those limitations, it is possible to identify some principles of the Shared Societies initiative with proxy variables in order to quantify certain social phenomena. The literature presents trends concerning social cohesion, the relationship between institutions and economic growth and productivity, and the costs of fractionalization, which support the assertions of the Club de Madrid's (2010, p. 6) guiding principles. The literature also clearly identifies certain public policies that are more suitable for both economic growth and social cohesion-those goals promoted by the Shared Societies initiative. A careful review of the economic literature tells us that creating a shared society leads to economic benefits, provided that certain conditions are met and certain policies implemented.

\section{CONSTRUCTING THE ECONOMIC ARGUMENT}

Constructing the economic argument for shared societies is challenging. Economics prefers to study quantifiable phenomena, and yet many of the tenets of a shared society pose problems in terms of valuation. For instance, it is difficult to establish values for cultural variables, and it is equally challenging to find literature that uses relevant, trustable, and high quality proxies for cultural variables. For that matter, it is not always obvious whether different economists mean the same thing when they use instruments for terms like "culture," as the definitions for cultural variables vary across time, space, and cultures (Glaeser 2005). Glaeser (2005) further notes that even ethnicity proves challenging, as perceptions about ethnicity or social identity, in general, are apt to shift over time. In general, while there is a large body of compelling sociological literature concerning identity and horizontal integrations, much of the study of ethnicity, race, and culture lies largely outside the purview of this paper.

For our purposes, it is important to find straightforward means by which to quantify social phenomena, and attempt to determine some concrete means by which a shared society can be measured and therefore serve to support an economic argument for social inclusion. There is an extensive body of literature that offers instruments for many social variables relevant to the Shared Societies initiative, and that serve as compelling instruments to measure social capital and social cohesion. 
The economic literature identifies four important dimensions that are important to the realization of a shared society:

The first section looks to policies of social inclusion around the world, and seeks to evaluate any quantifiable economic benefit from these policies. We find that there is very little empirical evidence that demonstrates directly quantifiable economic benefits from enacting socially inclusionary policies. Broader economic hypotheses behind social cohesion, however, inform our inquiry into the effect of institutions and social cohesion on economic growth as a logical starting point toward building an argument for shared societies.

Trust is the instrument most discussed in the literature. A shared society is a socially cohesive society; one in which people trust each other. Initiatives to improve intergroup trust are certainly a means by which a shared society can be achieved. Much of the literature discussed in later sections deals with the effects of trust on economic growth.

The economic rationale for shared societies also insists on the role of national and regional institutions, especially for economic growth and the improvement of social cohesion. The research demonstrates that there is an alignment of interest between economic growth and the promotion of a shared society. Many of the institutions that promote growth and investment are the same means by which to achieve a shared society.

The sixth section deals with institutional failures and the cost of fractionalization. An effective way of determining, from an economic standpoint, a more quantifiable definition of a shared society is to look at what a shared society isn't. Research demonstrates that fractionalized societies tax economic growth, stifle innovation, increase corruption, and prompt agents to employ racial and ethnic divisions for rent seeking purposes.

The final section of this paper summarizes our findings and determines policy alternatives that are in keeping with the findings in the economic literature.

\section{SOCIAL INCLUSION IN ACTION?}

Unfortunately, we can point to very few empirical data sets that support policies of social inclusion. Vinson (2009, p.9) specifically searches for applicable research that supports inclusionary principles and voices frustration with the lack of data. He concludes that "Quantitative studies reporting a statistically tight association between inclusory principles and practices and economic benefits are sparse." However, some general overarching factors emerge 
that support various shared society initiatives, and point to areas in which further study could greatly enhance empirical support for social inclusion. Notably, Vinson's (2009) research asserts that the benefits of putting marginalized people to work are generally greater than just the economic value of their input, as employing marginalized groups reduces crime and other social problems associated with poverty.

Inclusionary policies aimed at raising levels of participation in society across ethnic, cultural, gender, and income lines are generally considered of value to society if the benefits to society exceed the cost of implementation. While it is usually fairly simple to add up the cost of a policy initiative, listing and quantifying empirical benefits for such social policies is not at all straightforward. Positive economic outcomes can be demonstrated for a few specific inclusionary principles noted below, but the effects of enacting broader policies of social inclusion are discussed largely within the parameters of social observation and theory, and not necessarily economics. Many such programs may indeed be just and intuitively desirable, but data supporting their economic benefits simply do not exist. This means that an economic argument for shared societies will have to be built from existing research in areas somewhat peripheral to direct study of social inclusion. Much of the literature cites the social theory of Robert Putnam (1993; 1995), who determines that societies high in interpersonal trust and civic cooperation among individuals have more efficient goods provision in the public sector, and that a culture of trust facilitates growth. Building trust also serves to constrain the high costs of conflict (Putnam 1995). Barnes et al. (2004) also conclude that regional cultures of social inclusion are likely to encourage economic activity because diverse social groups are a source of potential innovation.

While there is little evidence that supports social inclusion, there is some-and there are several governments around the world seeking to implement socially inclusive policy. The Ministerial Advisory Committee for a Fairer Victoria (2009) also asserts that there is a link between social participation and an economy's overall capacity to produce, and that inclusion will reduce the gap between excluded groups and the rest of the population. The committee cites some evidence that strong investment in social and economic participation among teenagers in potentially excluded groups in Finland has resulted in lower poverty and a strong economy, but the connection is rather nebulous. The link between social participation and output is explored further in Section 4 of this paper. 
Jennson and Saint-Martin (2003) demonstrate a quantifiable influence of connectedness between disparate social groups on regional development, suggesting that there is an economic benefit to bridging ties across associational lines. They determine that making ties across associational lines can increase the production function. Their work concludes that building ties between groups has increased employment and output in four regions of France.

Extensive searches of international databases seeking empirical data that elegantly support inclusionary policies have come up empty. Vinson (2009) claims that this lack of empirical data might explain why some social programs and income transfers targeted at groups at risk for social exclusion across the European Union have often had unforeseen economic consequences. He notes increased income polarization, persistent poverty, and high unemployment in regions across the EU to suggest the shortcomings of current social policy in effectively incorporating marginalized groups. He further suggests that the failure of these policies bespeaks a need for relevant data evaluating specific inclusionary principals and their effect on growth. This view complements our desire to build a coherent economic rationale for shared societies.

While the determinations of research involving social inclusion are relatively narrow, what work there is touches upon the tenets of a shared society, and is a starting point in determining the means by which to encourage social inclusion and foster economic growth. Promise of concurrent economic growth is, after all, a compelling impetus for policymakers to consider inclusionary policies. The relationship between trust across associational groups and its ties to productivity is a keystone to building the economic argument for a shared society-so is the relationship between trust and cross-group association and collective action among diverse ethnic and linguistic groups. Terms of access to labor markets also require study. However, further data is needed to demonstrate exactly which groups' livelihoods are obstructed by lack of access to labor markets and enterprises, skewed or corrupt land ownership laws, or other avenues of social exclusion (United Nations Economic and Social Commission for Western Asia-UN-ESCWA 2007). There is also a need to explore the connection between economic inequalities and structural norms in societies, such as those that forbid the education of women. It is hard to argue that marginalizing half of any society makes economic sense.

UN-ESCWA (2007) notes, however, that there are "drawbacks to applying ideas concerning social exclusion based on economic and social experiences in post-industrialized countries" (UN-ESCWA 2007, p. 11). Given that social inclusion encompasses social rights and 
equal participation in socioeconomic development, ESCWA (2007) maintains that better indicators are needed in order to instrument for social participation than traditional measures of consumption and social provisions. Their report calls for evaluation of "bottom up" data on social and economic aspects of living standards relating to income poverty and human poverty, as well as the feasibility of the provision of services such as education, health care, transportation, and infrastructure to the socially excluded. To do this, it will be beneficial to determine how groups in society encounter barriers to accessing basic services and labor markets, or otherwise become marginal participants. The report stresses the importance of multi-disciplinary research to bridge many of the gaps between sociology and economics to link social inclusion to positive economic outcomes.

More research will hopefully corroborate the assertion that social inclusion is likely to encourage economic creativity and release the potential of previously excluded groups and to contribute to the goal of creating societies where "equity is no longer viewed as an issue of distribution of wealth but also of production of wealth" (Employment Equity Act Review of the Canadian Human Resources and Skills Development, Section 5). Such analysis might enable economists to build simpler "cost benefit" models for the social inclusion of various excluded groups. Furthermore, greater attention could then be directed to the means by which institutions, political rights, and economic processes interact to generate both higher standards of living and social cohesion. Subsequent sections in this paper corroborate the idea that under certain conditions, ethnically diverse groups can have higher levels of output. Our research has determined that trust and institutions interact to foster environments favorable to social inclusion.

\section{TRUST, SOCIAL CAPITAL, AND ECONOMIC GROWTH}

Given that the goal of a shared society is to give people the opportunity to participate fully, we look at studies of social cohesion in order to establish a link to economic growth. The literature on social cohesion uses instruments for trust and civic cooperation as the two measures that determine a society's level of social capital. The centerpiece of Knack and Keefer's (1997) analysis is the idea that a society in which social capital is high is one in which levels of interpersonal trust, as well as civic cooperation of individuals, is high. There is evidence in their research that illustrates the importance of trust. Trust facilitates transactions, which encourage 
and foster economic growth. Levels of trust and civic cooperation are a useful starting point in seeking the means by which the concept of a shared society can be quantified.

One way this paper seeks to build a more quantitative measure of shared societies is through the body of work which seeks to quantify the concept of social capital. "Social capital" is a somewhat ambiguous term, more common to political science and sociology, but is defined in the above article as an aggregate of the measure of Knack and Keefer's (1997) instruments for interpersonal trust and civic cooperation in a given society. We also point to the relationship between trust and civic cooperation and economic growth as a proxy measure for shared societies. The terms "trust" and "civic norms" are measured in the literature discussed in this paper in accordance with definitions and valuations presented by the World Values Surveys (WVS) conducted in 1990-91 across 29 different market economies. The WVS is a noncontroversial source for measuring trust within countries. There are obvious valuation problems in measuring trust, and Knack and Keefer (1997, p. 1255), quoting Solow (1995, p. 38), state succinctly that "if 'social capital' is to be more than a 'buzzword,' it must be measurable, even if inexactly." "Trust" is here quantified by asking respondents the following question: "Would you say that most people can be trusted, or that you cannot be too careful in dealing with people?" Their measure for "civic norms" is based on responses to questions regarding the perceived acceptability of several activities, namely, claiming government benefits falsely, avoiding paying a fare on public transport, cheating on one's taxes, keeping found money, or failing to report damage done to a parked vehicle.

These measures of civic norms are also strongly and positively related to economic growth. They demonstrate that a 10-percent rise in the trust coefficient leads to a 0.8-percent increase in GDP per capita across the countries surveyed. A 4-percent rise in civic norms translates to a 1-percent increase in growth in GDP per capita. There is also a strong and positive link between an increase in trust and investment. A 7-percent rise in trust in a country is correlated with a 1-percent rise in investment spending as a percentage of the GDP. Such findings are demonstrated across a large body of economic literature that explores the links of trust and civic norms to economic growth (Putnam 1993). The findings also repeatedly demonstrate a strong and significant relationship between trust and civic cooperation and output per worker. In every instance, higher levels of trust and civic norms are correlated with higher economic growth, on a macro level, and significantly higher levels of output per worker, on a micro level. 
Higher levels of trust and civic cooperation among populations have an economic impact, as economic growth depends on trust in a number of ways, mostly in terms of trust's role in reducing the transaction cost of economic activity. The fundamentals of economic activity are contingent upon an individual's ability to rely on the future actions of others. As Arrow (1972, p. 357) points out, "much of the economic backwardness in the world can be explained by lack of mutual confidence." Indeed, economic activity is inherently unstable. If trust can reduce the volatility of economic activity, trust should therefore cause more economic activity and therefore growth, everything else being equal.

Conversely, the exchange of goods and services for payment is thwarted by lowered levels of trust. In low-trust environments, it becomes difficult to establish employment contracts in instances where oversight might be difficult. Low trust thwarts investments, especially those that rely on assurances from governments or banks not to expropriate assets. In this sense, low trust environments can discourage innovation (Clague 1993). Hall and Jones (1999) posit that trust is integral to anonymous market exchange and reduces the need for contracts. Lack of trust, then, raises transaction costs and reduces the benefit from labor and the gain from trade. It acts as a tax on development, because where trust is low, agents have to spend resources to protect themselves from predatory actions by other agents.

Knack and Keefer (1997) conclude that high-trust environments can substitute for overly formal institutions and lower the costs for firms and individuals in the establishment of contracts. High-trust environments make it easier for individuals to protect themselves from litigation and expropriation, as litigation and expropriation are simply less common. In higher trust environments, they note, agents can adopt longer and more appropriate time horizons for investment decisions, because long-term gain becomes more attractive than rent seeking, or short-term gains, which undermine economic stability. Similarly, they conclude that environments with greater trust spend public money more effectively, as in socially cohesive societies, there is less incentive to engage in rent seeking at the expense of another group. Hightrust environments improve the quality of the overall workforce, as employers can focus more on the merits of potential employees and less on their level of "trustworthiness," which, in fractionalized societies, is generally based on blood ties or personal knowledge. In low-trust environments, the effective pool of labor available to employers is smaller and less skilled than in high-trust environments. 
There are a few notable outliers within the studies whose performance across a few decades only solidifies the relationship between trust and growth. Nigeria, for example, is among the lowest in levels of trust and civic cooperation among the countries surveyed by the WVS. Despite fairly robust growth between 1960 and 1970 due to the discovery of oil, by 1980 the Nigerian economy was again performing very poorly. Knack and Keefer's (1997) findings suggest that the squandering of this economic windfall can be attributed to the low levels of trust and civic cooperation within Nigeria. Low trust affects the time horizons adopted in deciding how to allocate resources. Low-trust environments favor consumption over investment of revenue. In Nigeria, this evaporation of vast profits points to the importance of creating hightrust environments. Not only might high-trust environments be right or just, economic viability depends on them. Fractionalization and low trust also thwart investment. In fractionalized societies, elites often maintain power by diverting resources to supporters who then expropriate funds for investments outside of the country. Mexico and Brazil saw such "capital flight" between 1960 and 1970 and later in the 1980s. Each benefited from temporary economic windfall that was undercut and eventually undone due to factors that follow low levels of trust and civic cooperation.

Tabellini's (2005) work illustrates compelling examples of the historical development of what Club de Madrid (2010, p. 6) refers to as "vicious cycles." Low trust and poor institutions continue to feed off of each other. Low trust leads to ineffective institutions, which, in turn, further fractionalize societies. The legacies of institutions often act as intermediaries between trust and economic growth, as institutions can shape levels of trust and civic cooperation over time. $^{2}$

Environments in which the diffusion of social capital ${ }^{3}$ is encouraged are a key aspect to the promotion of a shared society. It is important to explore the determinants of social capital, i.e., trust, civic norms, and culture. Tabellini's (2005) model focuses on various instruments for culture and links them with economic growth across regions of Europe. Each instrument for the measurement of social capital variables that facilitate growth is also a trait that is favorable to the implementation of a shared society. A look at these traits is an encouraging means by which

\footnotetext{
${ }^{2}$ Institutions will be discussed separately in a later section, but his work uses the World Values Surveys to further evidence the link between culture and economic growth.

${ }^{3}$ Tabellini (2005) expands the definition of social capital to include not only interpersonal trust and civic cooperation but also the four traits listed above.
} 
the gap between social capital and institutional means to achieving a shared society might be bridged.

1) Trust: facilitates market exchange and reduces the need for contracts.

2) The conviction that individual effort is likely to pay off: Those in less hierarchical societies are more likely to view success as related to hard work and innovation rather than to luck or uncontrollable external events (Banfield 1958).

3) Generalized vs. limited morality: Hierarchical societies tend to have more limited morality, according to World Values Surveys. ${ }^{4}$ It is widely held that liberal democracies foster diffused development and that people within a democratic society apply abstract rules of good conduct in favor of limited morality.

4) Obedience: Coercive cultural environments, ones in which violence is used to control people, stifle cooperation within a group.

The link between additional measurements of culture and their effect on economic growth is compelling. Not only does Tabellini (2005) link cultural traits and economic development in the past, but he finds that specific institutions have shaped cultural traits that have, in turn, fostered economic growth. In exploring the historical legacy of institutions, data support the correlation between the diffusion of a generalized morality, or trust, and economic growth (Tabellini 2005). Social capital traits are strongly correlated with economic outcomes in a wide sampling of countries.

The links between institutions, which are easier to examine and measure than cultural traits such as trust, obedience, or morality, put the economic arguments for a shared society on much less shaky ground. There are a number of authors who make the link between historical institutions and culture. Putnam (1995), as well as DeLong and Shleifer (1993), emphasize that the evolution of liberalism goes hand in hand with a diffusion of a generalized morality. Measures of the attributes of political institutions are always strongly correlated with measures of culture. Tabellini (2005) finds that historical instruments such as "constraints on the executive," "accountability of executive powers," and "political checks and balances" throughout history consistently correlate with the measures of culture and social capital which, in turn, explain current economic development.

\footnotetext{
4 "General morality," according to the WVS, measures the likelihood that a person will behave "morally" to everyone. "Limited morality" measures the likelihood that a person will only behave "morally" to those whom he is immediately accountable, i.e., family and close associations.
} 
Levels of trust and civic cooperation, however, are nearly always considerably lower in ethnically heterogeneous societies. The literature repeatedly finds that fractionalization along ethnic lines correlates to significantly lower levels of trust and civic cooperation than are found in ethnically homogenous societies. It is also crucial to note, however, the many ethnically heterogeneous societies that are also economic powerhouses and the many ethnically homogenous societies that are economic failures. No one could argue the ethnic homogeneity of North Korea, for example. Of course, the population of the United States is very diverse and is the largest economy in the world. The question is, why? There must be other channels through which trust and civic cooperation foster economic growth. The repeated mention of institutions in the literature on trust and civic cooperation lead us to further explore the relationship between institutions and economic growth. We find that institutions are central to fostering environments of trust and are possible means to remediate the lack of trust in ethnically heterogeneous societies. There is indeed evidence of what the Club de Madrid (2010, 3) refers to as a "virtuous cycle." We explore the definitions and significance of the virtuous cycle below.

\section{INSTITUTIONS, TRUST, AND ECONOMIC GROWTH: THE VIRTUOUS CIRCLE EXPLORED}

The "virtuous cycle" is a term coined by the Club de Madrid (2010, p. 3). It is meant to articulate the proposition that governments that engage in and invest in all members of society foster an environment that maximizes the economic contributions of all individuals. When governments act on behalf of their entire populations, people are more likely to identify with and support the common good. If more people are engaged in supporting the common good, governments will be more stable and therefore better able to act on behalf of all of their citizens. A vicious cycle, conversely, reflects a government that is not interested in investing in all members of society. Some fractions of society are therefore unable or unwilling to contribute to the common good. Some might seek to undercut the common good for their own benefit. Governments will therefore be less stable and unable to act on behalf of all of its citizens.

The correlation between institutions and social capital and social capital's concurrent benefit to economic growth offers insights that encourage promotion of a shared society. Acemoglu, Johnson, and Robinson (2001) spot a definite and quantifiable pattern in the existence of certain institutions and economic growth. They cite consistent property rights, an 
absence of confiscatory tax policies, low risk of expropriation, low levels of corruption, and limited barriers to trade as institutions favorable to economic growth.

Acemoglu, Johnson, and Robinson's (2001) study of institutions is indicative of this trend, and isolates "clusters of institutions" that mitigate ethnic fractionalization as well as promote economic growth. There is definite room to expand the research on the clusters of institutions and each one's effect on economic growth, as there is a vast literature on the effect of each institution on economic outcomes. There are also correlations between individual institutions and social cohesion across much of the literature discussed in this review. ${ }^{5}$ There is compelling evidence for both virtuous and vicious cycles.

Improvements in education are a real linchpin in achieving a shared society. Glaeser (2005) finds that better educated populations and environments that contain better information technology have lower costs associated with finding and vetting information about other ethnic groups. Additionally, better educated populations generally have greater knowledge of politics and public affairs. Societies in which a large number of citizens are aware of public affairs keep corruption in check. In a cross-country analysis, Knack and Keefer (1997) find that higher levels of school enrollment are consistently and positively related to growth. All of these factors increase the levels of social cohesion and, at the same time, demonstrate favorable economic outcomes.

Knack and Keefer (1997) extensively analyze policy and other links through which various instruments of social capital might have an economic effect. Their work concludes that trust and civic cooperation are significantly higher in countries with formal institutions that effectively protect property and contract rights. Not surprisingly, they find also that trust and civic cooperation are higher in societies that are less polarized along lines of class or ethnicity. The body of research nonetheless points out again and again that these institutions mitigate lower levels of trust and civic cooperation in ethnically heterogeneous societies. They also find that these same institutions encourage economic growth and output per worker. Knack and Keefer (1997) conclude that a body of property ownership laws, as well as a level playing field for signing and negotiating contracts of all kinds, is associated with higher levels of social

\footnotetext{
${ }^{5}$ See Acemoglu, Johnson, and Robinson (2001), Knack and Keefer (1997), Hall and Jones (1999), and Alesina et al. (2003).
} 
capital and is evidence of a strong concurrent economic impetus. This is an excellent start in the promotion of a shared society.

In many fractionalized societies, marginalized groups cannot own property. Sometimes, the legal system is skewed so much as to prevent full representation of the interests of certain groups. The consistent and equal ability of citizens to enter contracts and the ability for all citizens to see that the protections and benefits outlined in those contracts are enforceable are key elements in promoting a shared society. Our research demonstrates that those same factors not only promote growth, but also increase levels of trust and civic cooperation. It is plausible that further inquiry will more concisely demonstrate the precise means by which alterations to specific institutions will enable nations to further implement a shared society. For the time being, however, it is clear that many of the institutional objectives that encourage growth also increase social capital.

Acemoglu, Johnson, and Robinson (2001) reach conclusions similar to others in their studies of the institutional legacies of colonizers. Interestingly, the authors choose mortality rates of colonizers in a cross-country analysis as a means of exogenous variation in institutions and their ties to economic performance. They determine that in colonies such as Nigeria, Cote D'Ivoire, the Belgian Congo, and others, the prevalence of diseases (mostly malaria and yellow fever) meant that colonizers could not feasibly settle permanently and therefore set up extractive institutions. ${ }^{6}$ The rule over indigenous populations was absolute, individual liberties were limited, and confiscatory tax policies were established. All institutions served the singular purpose of transferring as much wealth as possible from the colony to the colonizer. In colonies where mortality rates of Western settlers were comparatively low, such as Canada, Chile, New Zealand, or Australia, colonizers built "mini-Europes," with governments comprised of institutions that protected property rights, limited the authority of the executive, and where extractive institutions would be counterproductive to the colonizing population. Acemoglu, Johnson, and Robinson (2001) highlight the persistence of these institutions. The nations that had high levels of settler mortality have the lowest GDP per capita today. It is clear through examining the legacy of extractive states versus those of the "mini-Europes" that the institutions a society creates have lasting effects on the long-term stability and sustainability of an economy.

\footnotetext{
${ }^{6}$ An "extractive institution" is a body of law designed for the sole purpose of transferring wealth from a colony to a colonizer.
} 
This dichotomy in institutional quality is evident in the contrasting legacies that institutions brought by Europeans have created. The effect of extractive institutions on social cohesion is relatively straightforward. The authors point to Brazil, which didn't outlaw slavery until 1888, or to policies of forced labor in Mexico or Zaire as evidence of institutional legacies that stifle growth. Such institutions, of course, also run counter to the vision of a shared society. They maintain that this institutional persistence can account for the fact that many Latin America and African nations have low or negative growth. La Porta et al. (1999) have done extensive work on the legal origins of colonizers and their effect on the quality of current institutions in former colonies around the world, but mortality of colonizers has turned out to be a key exogenous measure of those institutions.

Tabellini (2005) estimates the effect of specific cultural traits that are generally regarded as favorable to economic growth and to the effective functioning of democratic institutions. The analysis uses literacy rates in the past, as well as several measures of political institutions, and links them to current measures of culture according the WVS surveys in 69 regions across Europe. The model demonstrates that past literacy rates and regional political history are correlated with culture. Culture, in turn, influences per capita development. In his cross-regional and cross-country analysis, literacy rates in 1880 are strongly and positively correlated with current per capita output. A 1-percent increase in literacy rates in 1880 translate into a 0.8-0.9percent increase in current output per capita. Similarly, his model creates an institutional framework that determines strong and positive relationships between historical political institutions and current responses to WVS surveys. There is also a strong correlation between past institutions and current GDP per capita figures. The model determines, in effect, that institutions shape culture, and improvements in cultural instruments increase economic growth. Greater economic growth allows a society to afford better institutions, which, in turn, further shape culture. Tabellini's (2005) work rather succinctly encapsulates the concept of a virtuous cycle.

The results of the models indicate that a society can realize substantial economic gains by improving its institutions. If, for example, Nigeria were to improve its cluster of institutions to a level on par with those of Chile, it would lead to a 700-percent increase in income per capita. This comparison is somewhat disingenuous, or perhaps overly simplistic, but it certainly underscores the importance of quality institutions. Japan's Meiji restoration or the rise of South Korea after the Korean War are excellent examples of the impact improving institutions has on 
fostering growth. ${ }^{7}$ Nobody could dispute the disparity in institutional quality between North and South Korea, and they are both comprised of the same ethnic group. To that end, North Korea is one of the most ethnically homogenous countries on earth, yet its economic policies are utterly catastrophic.

The unfortunate shortcoming of the "cluster of institutions" model is that while improvements in clusters of institutions corresponds with a higher GDP per capita, it isn't always clear what exact steps would lead to improvement of these institutions, or which specific institutions might affect growth more positively than others. It is also worth noting that institutional changes often affect cultures in ways that were not intended. We believe that shared societies will most effectively be brought about through institutional channels. Since early institutions affect the future accumulation of social capital, it seems like the best place to start in implementing a shared society. It is clear that greater work is needed on determining the most effective institutional means by which to encourage social inclusion, as the implementation of shared societies is most likely realized through institutional means on the international, national, and local level.

\section{FRACTIONALIZATION: ROOM FOR IMPROVEMENT}

When considering the economic benefits of a shared society, it is important to examine the economic costs of fractionalization, as the two terms stand in sharp contrast. Landmark research by Alesina et al. (2003) and Alesina and La Ferrara (2005) has proven useful in this regard, and its findings are corroborated across several follow-up papers. ${ }^{8}$ Their research demonstrates the correlations between ethnic conflict and poor governmental and economic performance. Its shortcomings prove useful, as well, in pointing out gaps in research necessary to further the building of an economic rationale for a shared society.

Alesina et al.'s (2003) model instruments for ethnic fractionalization by using Easterly and Levine's (1997) ethnolinguistic fractionalization (ELF) variable. The variable reflects the likelihood that two randomly selected individuals from a population will belong to two different ethnic groups. ${ }^{9}$ The variable for linguistic fractionalization is measured in the same way, using

\footnotetext{
${ }^{7}$ See Sen (1999).

${ }^{8}$ See Alesina et al. (2003), Alesina and La Ferrara (2005), La Porta et al. (1999), Canning and Fay (1993), and Mauro (1998).

${ }^{9}$ See Easterly and Levine (1997).
} 
the classifications of language given by the Encyclopedia Britannica's list of "mother tongues" across 201 countries. Alesina et al.’s (2003) analysis measures ethnic and linguistic fractionalization to determine their effects on growth, institutional quality, and productivity.

The table below, taken from Alesina et al. (2003), indicates that ethnic and linguistic fractionalization are correlated with poor institutional quality and low (and sometimes negative) economic growth. They instrument for economic performance by calculating GDP growth per capita as well as the average black market premium for goods and services. They then run these variables against fractionalization coefficients for 190 countries. The link to institutional quality is illustrated by calculating average levels of schooling as well as for the number of telephone lines per 1000 workers, and running them against the same fractionalization coefficients. The analysis demonstrates that higher levels of ethnic fractionalization result in less "desirable" levels of every variable. Average growth is much lower, and black market premiums are much higher. The workforce is consistently less educated, and infrastructure (instrumented as telephones per worker) is considerably poorer

\begin{tabular}{|c|c|c|c|c|c|c|c|}
\hline Country & $\begin{array}{l}\text { Average } \\
\text { Growth in } \\
\text { 1980's }\end{array}$ & $\begin{array}{l}\text { Average } \\
\text { Black } \\
\text { Market } \\
\text { Premium } \\
\text { in 1980's }\end{array}$ & $\begin{array}{c}\text { Average } \\
\text { Years of } \\
\text { Schooling } \\
\text { of Labor } \\
\text { Force, } \\
\text { 1980's }\end{array}$ & $\begin{array}{c}\text { Telephone } \\
\text { Lines Per } \\
1000 \\
\text { Workers, } \\
\text { 1980's }\end{array}$ & $\begin{array}{l}\text { Government } \\
\text { Balance to } \\
\text { GDP, 1980's }\end{array}$ & $\begin{array}{l}\text { Corruption } \\
\text { (1 to } 10) \\
\text { Higher } \\
\text { Means } \\
\text { Corruption }\end{array}$ & $\begin{array}{c}\text { Ethnic } \\
\text { Fractionalization } \\
\text { Coef. }\end{array}$ \\
\hline \multicolumn{8}{|l|}{ Africa } \\
\hline Botswana & $7.0 \%$ & $16 \%$ & 3.3 & 27 & $11.2 \%$ & 6.5 & .41 \\
\hline Ethiopia & $0.0 \%$ & $76 \%$ & $\mathrm{n} / \mathrm{a}$ & 4 & $-7.1 \%$ & 4.3 & .72 \\
\hline Nigeria & $-3.3 \%$ & $76 \%$ & $\mathrm{n} / \mathrm{a}$ & 2 & $0.3 \%$ & 3.0 & .85 \\
\hline \multicolumn{8}{|c|}{ Latin America } \\
\hline Bolivia & $-3.3 \%$ & $39 \%$ & 5.0 & 46 & $-14.4 \%$ & 2.8 & .74 \\
\hline Chile & $1.9 \%$ & $16 \%$ & 7.0 & 84 & $-0.2 \%$ & 5.3 & .19 \\
\hline Guyana & $-2.4 \%$ & $131 \%$ & 5.6 & $\mathrm{n} / \mathrm{a}$ & $-39.7 \%$ & 2.0 & .62 \\
\hline
\end{tabular}

Alesina et al.'s (2003) model shows that both ethnic and linguistic fractionalization, especially, have a strong negative correlation with levels of schooling, financial depth, fiscal surplus, and the number of telephones per worker. In instances where fractionalization is higher, the variables are considerably lower-which, in turn, it is surmised, reduces growth. Controlling for each of the variables effectively eliminates the correlation between fractionalization and growth, suggesting that there is no direct causality between fractionalization and growth or government quality. The analysis highlights different avenues by which fractionalization and ethnic conflict may affect development, and suggest that they may do so through institutional 
channels. The link is precarious, however. That the link disappears when conditioning for institutional variables may be due to outliers or some omitted variables. Further research is needed to test the robustness and establish a definite empirical thread between fractionalization, institutions, and economic growth.

Nevertheless, the research offers some historical explanation for the correlations. They also isolate outliers such as Chile and Botswana as a means by which to expand on or refute some previous determinants of poor growth established by La Porta (1999), such as origins of a country's legal system, or its proximity to the equator.

The correlation between fractionalization, institutions, and growth across countries is clear, though ambiguous causality prevents us from pointing to concrete economic imperatives for the creation of a shared society. While determinants for this link can be surmised through historical context and social theory, quantifiable data sets and empirical proof draw rather limited conclusions. It is one thing to establish that there is a link between ethnic heterogeneity and poor economic, institutional, and government performance, and it is quite another to be able to quantify concrete measures of the actual costs of fractionalization.

It is possible, however, to extrapolate practical starting points for the implementation of a shared society from the research of fractionalization. If there are intermediate variables through which fractionalization affects growth, then intermediate variables can mitigate fractionalization's effect. For example, the link between education and a shared society's objectives has already been established. Glaeser (2005) determined that improved education and communication lowers the opportunity cost of verifying information about other groups. This lower opportunity cost thereby creates greater incentives to cross associational lines. He cites a survey in the US that determines that 7 percent of college educated Americans favored a law banning interracial marriage, whereas 37 percent of those with a high school education or less favored the ban. Ninety three percent of college educated Americans would vote for a black candidate for president, compared to less than 80 percent of those with a high school education or less. Similarly, improving means of communication is another means to lower the opportunity cost for members of groups in fractionalized societies to vet misinformation about other groups. Better means of communication in societies increases peoples' incentives to vet information about other groups. Increasing the number of telephones per worker may therefore also mitigate fractionalization. 
Further insight into possibilities for a shared society is evidenced by the welldocumented negative effect of fractionalization on economic growth. Alesina et al. (2003) notes that in societies fractionalized by ethnic, linguistic, religious, or, for that matter, income inequalities, associations tend to form along those fractionalizing lines. We mentioned in Section 4 that interpersonal trust is considerably lower in more diverse societies. In countries where there are lower levels of interpersonal trust, Glaeser (2005) states that there is a far greater incentive to renege on policy agreements with other ethnic groups. Additionally, fractionalized societies are less likely to share common frames of reference for expectations about future behavior of other groups. Glaeser (2005) concludes that lack of trust and lack of common frames of reference among populations leads to rent seeking at the expense of the public good. Incentives to renege on policy agreements and lack of mutual expectations about future behavior often plague fragmented groups within a country. Rent seeking behavior further undermines trust and acts as a tax on output. ${ }^{10}$

Economic research also documents a strong link between fractionalization and government quality. La Porta (1999), for instance, asserts that greater fractionalization always leads to a lower quality of government, i.e., indicators for corruption of public officials, property rights, a transparent legal system, and education, among others. The Democracy Index is also inversely related to ethnic conflict. ${ }^{11}$

Fractionalization may affect growth through the effect of ethnic conflict on the quality of institutions and government policy. Alesina's (2003) findings can be put in context using the historical narrative of some of the more fractionalized societies. Many countries high in ethnic and linguistic fractionalization, such as Nigeria, Ethiopia, Bolivia, or Guyana, have been beset by struggles that have impeded economic growth for generations. Conflict of preferences, racism, and prejudices among ethnic groups are wasteful, and can lead to exclusionary and counterproductive policy. Oppression of minorities can and has led to unrest and civil wars in Algeria, Angola, and Rwanda, for example, which has had disastrous economic consequences. ${ }^{12}$ Many examples around the world exhibit formations of vicious cycles that the shared society seeks to remediate. Ethnic fractionalization lowers the quality of institutions (Alesina et al. 2003). Institutions affect economic performance and shape culture. Culture and social cohesion

\footnotetext{
${ }^{10}$ See Knack and Keefer (1997).

${ }^{11}$ The Democracy Index is compiled by the Economist Intelligence Unit (EIU) and is an index that measures indicators of democracy across 60 different categories. See EIU (2011).

${ }^{12}$ See Blattman and Miguel (2010).
} 
affect output and economic growth, which, in turn, affects institutions. Tabellini's (2005) research of institutional persistence evidences this circular relationship between institutions and culture.

Specific examples are abundant. In Nigeria, much of the ethnic struggle can be traced to ethnic fractionalization between the Muslim north and the Christian south. Minority groups in northern Nigeria have been victims of persistent violence. Additionally, fragmented groups in the center of northern Nigeria and the Niger Delta perpetuate small scale conflicts along ethnic lines. The polarization between groups in Nigeria has led to disastrous economic policies, poor infrastructure, and high corruption. ${ }^{13}$ Nigerian people have to depend disproportionately upon a black market in order to procure goods and services, reflecting a failure of markets in addition to a failure of government. Telephone density is among the lowest in the world, and their bureaucracy is among the most corrupt. A perfect example cited by Maier (2000) is his exposé on the construction of the Ajaokuta Steel Complex, begun in 1979. Since its inception, the project has been beset by asset stripping, corruption, deliberate construction delays-and after the squandering of $\$ 8$ billion in public funds, it has yet to produce a single ton of steel.

Ethiopia has had revolving door regimes since its independence, which span the political spectrum from Marxist-Leninist to reformist. Ethiopians have endured ethnic conflict for centuries, and have one of the lowest growth rates in the world. Political and ethnic conflict have both caused and magnified ravaging epidemics of famine and AIDS. Much of the paltry aid and tax revenue the Ethiopian government collects has been absorbed by civil and international war. Ethiopia is also a perfect example of a country whose political associations are set up along ethnic lines. The Tigray minority dominates the government, despite accounting for only 6 percent of the population. The Tigray People's Liberation Front (TPLF) is an egregious rent seeker, having managed to siphon off revenue to accumulate extensive holdings in shadowy offshore endowment funds. The government claims credit for attempts to prevent ethnic conflict by decentralizing power. The TPLF claims to make an earnest attempt to address ethnic divisions in Ethiopia, but the fact is that of over 80 ethnic groups in nine different regions, the dominant group in each region works to marginalize local minorities.

Decentralization of authority is seen as a ploy to divide the TPLF's political opposition along ethnic lines and to undercut the authority of the central Ethiopian bureaucracy.

${ }^{13}$ See Maier (2000). 
Interestingly, Botswana is the exception to many of the poor economic outcomes that plague much of Sub-Saharan Africa. They have experienced high growth, and black market premiums are low. The government runs a surplus and is relatively uncorrupt. For the region, however, Botswana has relatively low ethnic diversity.

The data shed new light on the ethnic diversity in Latin America and the Caribbean, as well. Alesina et al. (2003) expands the ethnic and linguistic fractionalization indices to distinguish between many ethnic groups which were previously lumped together. ${ }^{14}$ In light of new data sets, poor growth and political instability can be attributed to previously un-quantified fractionalization. Whites controlled Bolivia until 1952, whereupon an Indian revolt redistributed land and abolished most of the exclusionary policies implemented by whites. Bolivia endured rampant political instability and frequent coups for the next thirty years. Institutional legacy is indeed persistent. Despite having been ruled democratically since 1982, Bolivia still exhibits low growth, poor provision of public goods and services, and predatory police and judges.

Guyana is another nation beset by corruption and poor growth outcomes since its independence. Afro-Guyanese and Indo-Guyanese are the two predominant ethnic groups, and political mobilization in Guyana has taken place along ethnic lines. Due to fractionalization, any attempt at consensus among ethnic groups has been eviscerated by rent seeking. As a result, Guyana is one of the most corrupt countries in the world.

The simple fact remains, however, that not all ethnically diverse societies are a failure. Not all ethnically homogenous societies are a success. The challenge is to pinpoint the means by which to mitigate the negative effects of fractionalization, and whether those channels of mitigation further serve as a means by which to promote shared societies. In subsequent work, Alesina and La Ferrara (2005) explore why some diverse societies succeed. After all, research exists that identifies a relationship between individual heterogeneity and innovation and productivity. ${ }^{15}$ Diversity's relationship to the production function is an area of promising future research. Future research might also further quantify the trade-offs between the positive benefits of diversity and the possible costs that diversity imposes due to differences in communication and culture.

\footnotetext{
${ }^{14}$ Before Alesina's (2003) work with the ELF variable, the data of ethnic and linguistic fractionalization most typically used was published in the Soviet Union in 1964 in the Atlas Narodov Mira.

${ }^{15}$ See Hall and Jones (1999).
} 
There is a relationship between diversity and productivity evidenced by the literature that might help to explain the economic success of some ethnically heterogeneous societies. It is asserted in the research on diversity and production that diversity only leads to higher productivity when conflict is minimized and communication is maximized. Research by Hong and Page (1998) determines that more diverse groups of people with limited abilities can outperform homogenous groups of high-ability problem solvers. O'Reilly, Williams, and Barsade (1997) find a generally positive effect of racial and gender diversity on task completion, but only when controlling for communication among the groups. The effect of communication and conflict management on productivity among diverse groups is a compelling explanation for the fact that some ethnically diverse countries are successes. Alesina and La Ferrara (2005) complement this connection by noting that advanced economies can realize the benefits of complementary skills of a diverse population, as richer societies have developed institutions that allow them to better cope with the conflict element that is intrinsic to diversity. Many richer societies have better-established "rules of the game," which enable them to reap the benefits of racial, gender, and cultural diversity. ${ }^{16}$

Inquiry into variety in productivity and its link to diversity offers an interesting avenue by which to build the argument for shared societies. Mankiw, Romer, and Weill (1992) explore diversity's effect on the aggregate production function and determine that human and physical capital only account for a small difference in output per worker across countries. The largest determinant of output is differences in productivity. Why then, do some countries have so much more productive workers than others? Hall and Jones (1999) attempt to answer this question, and their conclusions may help to determine why some heterogeneous societies are successful while others are not. Much of the differences in long-run economic performances throughout the world, they conclude, are determined by variations in "social infrastructure" across countries.

"Social infrastructure" is defined by Hall and Jones (1999, p. 84) as an instrument that quantifies "institutions and government policies that determine the economic environment within which individuals accumulate skills, and firms accumulate capital and output." Analysis of worker output across 127 countries confirms that accumulation of physical capital and the education level of a workforce are only a partial explanation for the vast disparity between productivity figures at the top and bottom of the global spectrum. In order to measure the effect

\footnotetext{
${ }^{16}$ See Jackson and Ruderman (1996).
} 
of social infrastructure on output per worker, they quantify social infrastructure by creating a variable that aggregates two indices. The first is the index of government anti-diversion policies (GADP) as calculated by the Political Risk Services Group, a company that provides risk assessment for international investors. ${ }^{17}$ The second is a measure of openness to trade established in 1988 by Sachs and Warner (1995). The Sachs and Warner index measures several criteria: whether non-tariff barriers affect less than 40 percent of trade, whether the average tariff is less than 40 percent, whether black market premiums are less than 20 percent, that a government is not socialist, and that the government does not monopolize major exports. Sachs and Werner (1995) maintain that policies to maintain free trade yield benefits in terms of specialization as well as the ability to adopt techniques from abroad.

The aggregate Social Infrastructure Index attempts to quantify the effects of diversions on productivity, and links incentives that encourage individuals and firms to produce new goods and services or to develop new production techniques with more or less favorable environments. The findings determine that aggregate institutional variables are fundamental to ensuring higher levels of productivity among workers. This is very much in keeping with Alesina and La Ferrara's (2005) determination that the benefits of ethnic diversity can only be realized when controlling for potential conflicts or differences in communication. It also dovetails with our findings relating to institutional means by which to foster economic growth discussed in Section 5.

Hall and Jones (1999) highlight government quality as the main determinant in creating social infrastructure. They also consider government the most efficient means by which to suppress diversion. Where suppression of diversion is effective, individuals and firms do not need to invest resources in avoiding diversion, and are therefore rewarded by the full amount of their labor (North and Thomas 1973). On the other hand, when social infrastructure is low, and where government manages diversion poorly, diversion acts as a tax on output and a disincentive to work by reducing the individual gain for one's labor. The link between governments and social infrastructure is elemental to the concept of a shared society, as in the Hall and Jones (1999) model, government is the central agent to increase or decrease social infrastructure. Governments have the power to make rules, so they can be an agent for diversions and predatory or rent seeking behavior through expropriation, through confiscatory

\footnotetext{
17 The indicators for which the index of government antidiversion policies instruments are: (1) law and order, (2) bureaucratic quality, (3) corruption, (5) risk of expropriation, and (5) government repudiation of contracts.
} 
tax structures, or as a result of the corruption of its officials, which reduces the marginal benefit of work. They can also act as agents for the suppression of diversions by establishing equal protection under the law, definitive property rights, oversight of public officials, and fair, transparent tax structures.

Countries with the highest levels of social infrastructure in Hall and Jones's (1999) model, namely Italy, France, (British) Hong Kong, Spain, and Singapore, are also among the highest in output per worker. The countries in the model that have the lowest levels of social infrastructure, namely Zaire (now the Democratic Republic of Congo), Bangladesh, and Haiti, are among the lowest. Output is 3170 percent higher in the highest than in the lowest. A change in an exogenous variable that leads to a 1-percent increase in social infrastructure leads to a 5.14-percent increase in output per worker.

These findings enable us to determine that adjustment to social infrastructure variables are not only inherently desirable to a shared society, but also have profound payoffs in terms of worker productivity. Improving the rule of law and bureaucratic quality or eliminating corruption can improve societies and can dramatically increase worker productivity. The corporate world has known this for a long time. The International Risk Services Guide is utilized by investors around the globe to determine levels of risk to capital in making foreign investments. ${ }^{18}$ The World Bank compiles similar data and regularly publishes matrices by which to calculate investment risk across countries. ${ }^{19}$ Social infrastructure drives rates of investment in physical and in human capital and thereby makes societies more productive. Of course, direct comparisons of the effects of diversity between post-industrialized Western societies and African villages is a bit disingenuous, but highlighting the potential benefits of diversity helps to form an idea of some of the underpinnings of the economic effects of diversity. If nothing else, variety in production can be isolated as a determinant in levels of productivity to showcase the potential benefits of diversity.

\footnotetext{
${ }^{18}$ The Political Risk Services Group publishes the International Risk Services Guide (IRSG), a publication which monitors 161 countries, rating a wide range of risks to international businesses and financial institutions. See Political Risk Services Group (2012).

${ }^{19}$ The World Bank has created a similar index to the IRSG. See World Bank (2012).
} 


\section{OTHER ECONOMIC APPROACHES}

The above sections have presented the case for shared societies through the lens of specific studies addressing certain defining features of shared societies. There is, however, a more diffuse body of knowledge in economics that, despite not addressing the issue of shared societies directly, can be used to draw conclusions pertaining to the Shared Societies Project. Most of what follows draws a parallel between the Shared Societies Project and what is commonly accepted regarding inequality. The advantage of linking the Shared Societies program to inequality is that the issue of inequality is well developed in economics. Most economic research would indeed justify a certain degree of "natural" inequality, which should not be corrected for. The arguments run as follows:

We have seen that a shared society is an inclusive society, so we should expect a shared society to be a more egalitarian society as opposed to a widely unequal society. By "egalitarian," it is meant that previously excluded individuals or groups would participate in a shared society's labor force and general economic process. But a "more egalitarian" society should also mean that those individuals or groups previously excluded would now participate in the labor force at the current rates of compensation-if only to avoid discrimination. Yet, there is no basis for believing that all excluded individuals would enter the labor force at the same prevailing rate. Even under the best circumstances of a period of high and sustained economic growth, leading to a massive accession to the labor market, only certain areas of the economy will expand and certain individuals benefit—and some more than others. Growth is always biased toward one or a few sectors that usually reap most of the benefits. As such, economic growth may lead to a divergence of incomes, which goes against the agenda of a shared society.

Introductory economic textbooks will say that inequality of incomes is also a normal state of affairs in economic life. Inequality has several causes, with unequal educational achievements being the chief one. Individuals possess different abilities and skills so that individuals arrive at different educational achievements; we should expect the most educated and most skilled to reap the better paying jobs, and the unskilled, least able, least educated, to have the worse paying jobs - therefore justifying the existence of inequality of incomes. Along those lines, introductory textbooks tell you, any observed increase in inequality must therefore come from a malfunctioning labor market, or from a well-functioning labor market in which the education premium has been rising. Certain key skills, for instance, especially those tied to high- 
growth sectors, have been exceptionally well rewarded on the labor market (like computer science and finance most recently).

Should such an explanation of inequality be true, the policy implications are immediately clear: one should provide for access to education as a public good, using all the policy tools possible_-but within limits. Minorities, especially, who are often left out of educational opportunities, should be encouraged to acquire skills. But no policy should force individuals to acquire skills that would be too costly to train for. A simple cost-benefit analysis proves that training individuals is only valuable if there is a commensurate market reward for it - we do not need to subsidize education and training in typistry, shoe repair, etc., any more than we need to give $\mathrm{PhDs}$ to the whole population. Under traditional economic analysis, such obsolete skills should disappear because they are really a burden of inefficiency to society. And promoting too much training or the wrong training to unable or unwilling individuals would only lead to a waste of tax resources.

In that sense, traditional economic research provides a certain boundary to the Shared Societies Project. If inclusion is a matter of achieving a less unequal society, one should be cautious not to try to reduce inequality to a point so low as to reach the point where the costs of lowering inequality outweigh the benefits of enjoying a shared society. Certain products and services we consume do indeed demand very little skills and education; it would be foolish to reward those skills at the same rate as skills in higher demand or skills that are more strategically important.

Another well-regarded economic model promotes the existence of a certain incompressible level of inequality. Most countries, and especially European countries, have developed and continue to develop through international trade. But what are the likely effects of international trade? First, it is likely to bring labor mobility, which will lower cross-country wage differences. Second, using trade as an indirect method of production allows for a reorganization of resource usage in a more efficient way: there are widespread gains from trade. But we should be warned: in a given economy, some sectors will gain from trade and others will lose. The traditional Hecksher-Ohlin-Samuelson model of trade, for instance, will insist on the overall gains from trade, but it will also insist on the fact that losers from trade will inevitably appear. Again, this simple economics model would certainly not justify within-group inequality; yet, there remains the fact that the mechanics of international trade lead to conclusions of internal divergence of incomes. In that sense, economic growth and international trade make up 
two threats to the Shared Societies Project because those forces may create, if left on their own, a pulling apart of society, as opposed to a greater feeling of belonging.

Yet, biased economic growth and international trade are unavoidable and should be embraced. To lessen their negative impact on the Shared Societies Project, one should devise plans to compensate for the likely rise in inequality of income they will generate. This appears as a much better alternative to turning our backs on the gains from trade or economic growth.

\section{CONCLUDING REMARKS}

This survey concludes by mentioning several trends that emerge from the economic literature on shared societies. Trust and civic cooperation are intrinsically linked to economic performance, though many societies most in need of an economic boost exhibit very low levels of trust. It is possible to determine, however, that certain institutional improvements can increase the levels of trust and civic cooperation important not only to the creation of a society in which all citizens can participate, but one that is economically vibrant and politically stable. Higher levels of trust allow people to fully realize the fruits of their labor. Trust enables firms and individuals to invest resources in their own people without fear that their capital will be stolen by a corrupt government or be destroyed by fractional infighting.

It is imperative when making the economic case for a shared society to note that many of the same institutions that foster growth are the very same means by which to create a shared society. The rule of law, legislative constraints on executive power, and steps to eliminate corruption in government and the legal system all have profound economic benefits in the long run. The key is to get people to view the long run instead of the short run, and the way to do that is to implement policies that enable citizens to come to all transactions with similar expectations. If different citizens in a society are treated differently in the legal system, or have different levels of access to labor markets or public goods (such as education or basic health care), those citizens will have less incentive to participate in the system that excludes them. They will then have greater incentive to undermine economic processes through mafia formation, black markets, or tax evasion. Such rent seeking is epidemic in fractionalized societies all over the world and stifles economic progress.

Indeed, empirical evidence points to emergences of both vicious and virtuous cycles around the globe, and highlights compelling possibilities for the implementation of shared 
societies. It has been demonstrated that past institutions influence trust and civic cooperation. It is also demonstrated that low trust and low civic cooperation can undermine the ability of governments to rule efficiently. Citizens who are disenfranchised or marginalized in society, in turn, refuse to participate in society. A society in which people refuse to participate suffers on two levels. In poorer countries, governments cannot effectively collect the revenue necessary for infrastructure and governance. In wealthier countries, governments often have to pay to "manage" the marginalized population. Our research concludes that it makes more sense to invest in human potential than in damage control.

We must acknowledge the difficulty in establishing a consistent valuation for many cultural variables, however, and must recognize the limitations of some of our conclusions. It is plausible, for example, that institutions are the channels through which ethnic diversity affects economic growth, but further research is needed in order to corroborate our preliminary findings. We must also address the paucity of empirical work that establishes rigorous empirical causation between social exclusion and economic outcomes. Yet, despite those limitations, we are confident that the general trends outlined in this review can serve as a framework for real means by which a shared society can be built.

There is no absolute rule, and no single variable should be taken at face value as promoting a shared society in isolation from other variables. Rather, shared societies seem to emerge from-and in return benefit from-a set of policies. We have also discovered promising avenues for further research, looking to the conditions in which diverse groups exhibit higher levels of productivity and exploring concrete means by which infrastructure improvements could encourage social inclusion.

All in all, a shared society is not something you wish for; it is something you build, and it can be built by seeking means to increase interpersonal trust and by seeking means by which government can act to eliminate diversion. A shared society is built of equitable institutions on a solid foundation of trust. 


\section{REFERENCES}

Acemoglu, D., S. Johnson, and J. Robinson. 2001. "The Colonial Origins of Comparative Development: An Empirical Investigation.”American Economic Review 91(5): 1369_ 1401.

Alesina, A., A. Devleeschauwer, W. Easterly, S. Kurlat, and R. Wacziarg. 2003.

Fractionalization. Journal of Economic Growth 8(2): 155-94.

Alesina, A. and E. La Ferrara. 2005. "Ethnic Diversity and Economic Performance.” Journal of Economic Literature 43(3): 762-800.

Arrow, K. 1972. "Gifts and Exchanges.” Philosophy and Public Affairs 1(4): 343-62.

Banfield, E. 1958. The Moral Basis of a Backward Society. New York: The Free Press

Barnes, J., J. Peck, E. Sheppard and A. Tickell. 2004. Reading Economic Geography. Oxford, Blackwell.

Blattman, C. and E. Miguel. 2010. "Civil War." Journal of Economic Literature 48(1): 3-57.

Canning, D. and M. Fay. 1993. "The Effects of Transportation Networks on Economic Growth." Columbia University Working Paper. New York, NY: Columbia University.

Clague, C. 1993. "Rule Obedience, Organizational Loyalty, and Economic Development." Journal of Institutional and Theoretical Economics 144: 393-414.

Club de Madrid. 2010. "Policy Perspectives on the Economics of Shared Societies." Shared Societies Project of the Club de Madrid Working Group Report.

http://www.clubmadrid.org/img/secciones/Policy_Perspectives_on_the_Economics_of Shared_Societies.pdf.

DeLong, B. and A. Shleifer. 1993. "Princes and Merchants: European City Growth before the Industrial Revolution.” Journal of Law and Economics 36(2): 671-702.

EIU. 2011. The Democracy Index. The Economist. https://www.eiu.com/public/topical_report.aspx?campaignid=DemocracyIndex2011

Easterly, W. and R. Levine. 1997. "Africa's Growth Tragedy: Policies and Ethnic Divisions." The Quarterly Journal of Economics 111(4): 1203-50.

Employment Equity Act Review of the Canadian Human Resources and Skills Development. 2001. http://www.hrsdc.gc.ca/eng/lp/lo/lswe/we/review/report/main.shtml

Glaeser, E. 2005. “The Political Economy of Hatred.” The Quarterly Journal of Economics 120(1): 45-86.

Hall, R. and C. Jones. 1999. "Why do Some Countries Produce So Much More Output per Worker than Others?" The Quarterly Journal of Economics 114(1): pp.83-6. 
Hong, Lu and S. Page. 1998. "Diversity and Optimality." Santa Fe Institute Working Paper. Santa Fe, NM: Santa Fe Institute.

Jackson, S. and M. Ruderman, Eds. 1996. Diversity in Work Teams: Research Paradigms for a Changing Workplace. Washington, DC: American Psychological Association.

Jenson, J. and D. Saint-Martin. 2003. "New Routes to Social Cohesion? Citizenship and the Social Investment State." Canadian Journal of Sociology 28(1): 77-99.

Knack, S., and P. Keefer. 1997. "Does Social Capital Have an Economic Payoff? A Cross Country Investigation." The Quarterly Journal of Economics 112(4): 1251-88.

La Porta, R., F. Lopez-de-Silanes, A. Shleifer, and R. Vishny. 1999. "The Quality of Government." The Journal of Law, Government, Economics and Organization 15(1): $222-79$.

Maier, K. 2000. This House Has Fallen: Midnight in Nigeria. New York, NY: Public Affairs.

Mankiw, G., D. Romer, and D. Weill. 1992. "A Contribution to the Empirics of Economic Growth.” The Quarterly Journal of Economics 107(2): 407-438.

Mauro, P. 1998. “Corruption and Growth.” The Quarterly Journal of Economics 110(3): 681712.

Ministerial Advisory Committee for Victorian Communities. 2009. Social Inclusion: The Next Step for a Fairer Victoria. Melbourne, Australia.

North, D. and R. Thomas. 1973. The Rise of the Western World. Cambridge, UK: Cambridge University Press.

O’Reilly, C., K.Williams, and S. Barsade. 1997. "Demography and Group Performance." Research Paper 1551. Working Paper Series. Stanford, CA: Stanford University.

Political Risk Services Group. 2012. International Risk Services Guide. http://www.prsgroup.com/prsgroup_shoppingcart/pc-39-4-international-country-riskguide-icrg.aspx.

Putnam, R. 1993. Making Democracy Work, Princeton: Princeton University Press

_ 1995. "Tuning In, Tuning Out: The Strange Disappearance of Social Capital in America". PS: Political Science and Politics 28: 664-83.

Sachs, J. and A. Warner. 1995. "Economic Reform and the Process of Global Integration." Brookings Papers on Economic Activity: 1-95.

Sen, A. 1999. Development as Freedom. New York, NY: Anchor Books.

Solow, R. M. 1995. “But Verify.” New Republic 213(11): 36-39. 
Tabellini, G. 2005. "Culture and Institutions: Economic Development in the Regions of Europe." Working Paper 292. IGIER, Bocconi University.

UN-ESCWA. 2007. Literature Review on Social Exclusion in the ESCWA Region. New York, NY: United Nations.

Vinson, T. 2009. Social Exclusion: The Origins, Meaning, Definition, and Economic Implications of Social Inclusion/Exclusion. The Australian Department of Education, Employment, and Workplace Relations. www.socialinclusion.gov.au

World Bank. 2012. Doing Business Report. http://www.doingbusiness.org/reports 